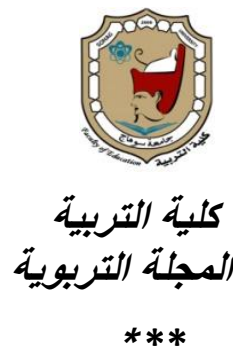

Open-Access Publishing النشر العلمى الافتتوح

$$
\text { بين التأييد والرفض }
$$

إعداد

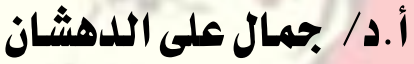

أستاذ أصول التربية

عميد كلية التربية جامعة المنوفية

المجلة التربوية ـ العدد الستوز ـ أبريل 19+19م

Print:(ISSN 1687-2649) Online:(ISSN 2536-9091) 
يمثل النشر العلمي الطريق العلمي والفاعل وأحد أهم المقاييس المستخدمة لتقدير مستوى الانتاج العلمي وأهم آليات مشاركته وإثراء المعرفة العلمية وإيصالها إلى من يحتاجها،

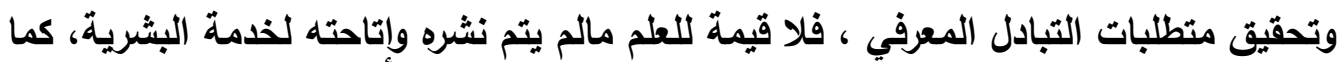
انه اصبح من أهم المعايير الدولية لتصنيف الجامعات، فمعايير تصنيف الجامعات اصبحت تعتمد في معظمها علي مساهمات اعضاء هيئة التدريس ونوعية وكمية المنشورات باسم الجامعة ومقدار اثر تلك المنشورات ومدي الاستثهاد بها من قبل الباحثين في مختلف دول العالم.

لذلك تهتم الجامعات ومراكز البحوث بنشر نتائج أبحاثهم العلمية في أوعية النشر المحكمة و التي تتبنى المعايير العلمية الرصينة من دوريات علمية متخصصة أو كتب أعمال المؤتمرات من أجل تبادل المعرفة و النتائج لكي تستمر الأبحاث و تتكامل نتائجها و أهدافها. وقد مر النشر العلمى بمراحل متعددة بداية من النشر التقليدى وخاصة بعد اختراع

آلات الطباعة ، التي ساهمت في إصدار مجلات ودوريات علمية متخصصة مطبوعة ، وتُخضع لعملية تقييم تحكيم جادة بمعرفة خبراء متخصصين ( تقييم النظراء ) ويعد الموافقة عليها يتم نشرها وتوزيعها على كل المشتركين حول العالم . ومرورا بالنشر الاكترونى بعد ظهور تكنولوجيا المعلومات (IT) ، وميع استخدام الحاسوب الآلي وشبكة الانترنت والاجهزة المحمولة ، والتى اعطت الفرصة لتبادل الخبرات و الربط و التقريب بين الباحثين حول العالم ، ونشر النتائج العلمية بنفقات اقل ، واختصارا للوقت ، وزيادة فى الكفاءة واللفاعلية فى استخدام المعلومات ، وتماشيا مع ايقاع الحياة فى

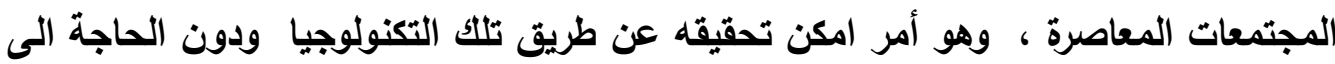

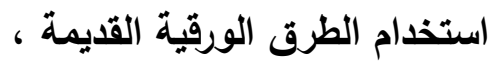
ووصولا الى ما نادى به البعض فى القترة الاخيرة بضرورة إتاحة كافة الأبحاث المنشورة لكل الباحثين حول العالم مجاناً Open Online Access - يث يعد نموذج الوصول الحر فى النشر العلمى من اكثر التغيرات الجوهرية اهمية فى النشر فى السنوات

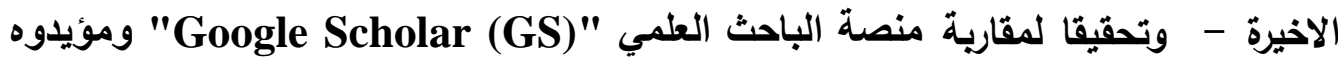
في العالم الأكاديمي عن "دمقرطة الانتاج العلمي وقياس التأثير" والتى اكدت على اعتبار أن أي بحث او وثيقة منشورة هي قابلة للقراءة والاقتباس بغض النظر عن الموضوع الذي الذي 


\section{النشر العلمى المفتوح Open-Access Publishing بين التأييد والرفض.}

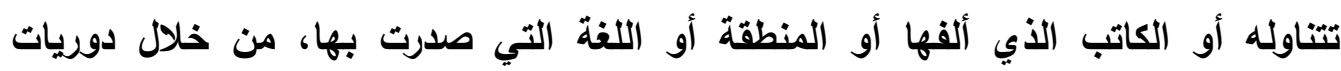
الوصول الحر( O A J ) ، والتى نالت من الأسس التي كاتت تعتبر راسخة في مجال النشر التهر

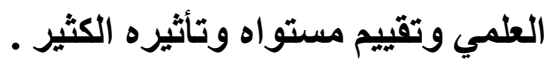

وقد برزت حركة الوصول الحر والنشر الحر في العقدين الأخيرين، نتيجة لثمراتها الكثير في الارتقاء بآليات تدفق المطومات، وقد قامت العديد من المجتمعات والمؤسسات بتبني هذه الحركة، واستثمار مقوماتها المختلفة، وذلك من أجل تيسير تدفق المعلومات ليس

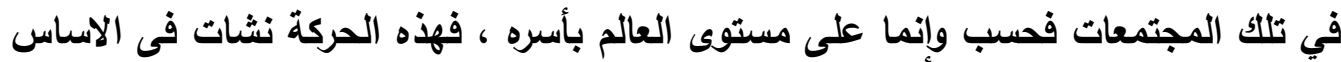

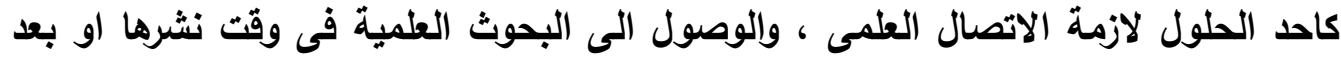
فترة قليلة من ذلك ، والتظلب على مشكلة ارتفاع تكاليف الاشتراك فى الدوريات التقليدية

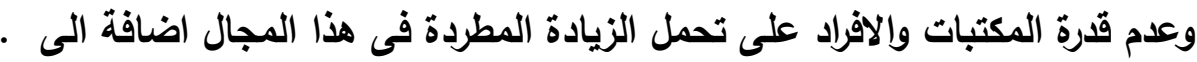
وفى الفترة الأخيرة نادى العديد من الخيرين في هذا العالم ، بضرورة إتاحة كافة

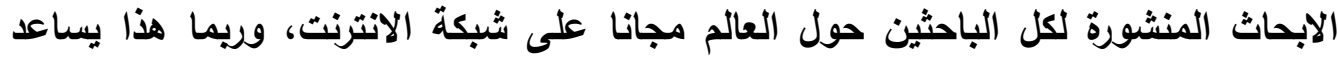
على تطور وتسارع عملية البحث العلمي وتقليل النفقات للوصول الى البحوث المنات المنشور.

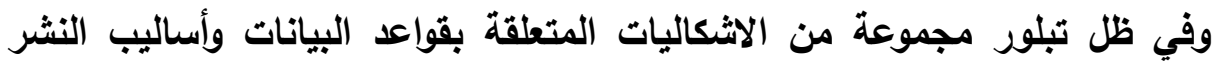

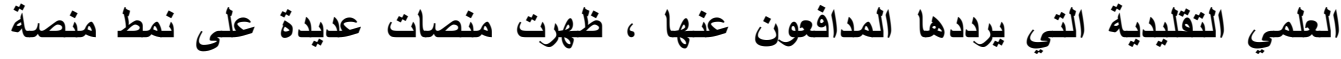

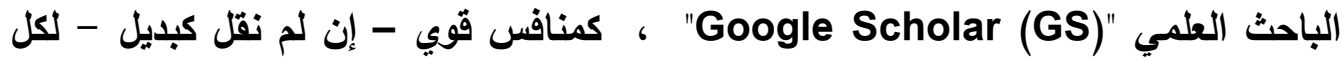
من "TR" و "Scopus". حيث يستفيد "GS" من قدرات محرك بحث Google على الوصول لكل ما ينشر تقريباً في العالم الرقمي من انتاج علمي في الدوريات والمجلات والكتب

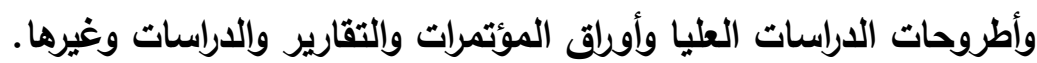

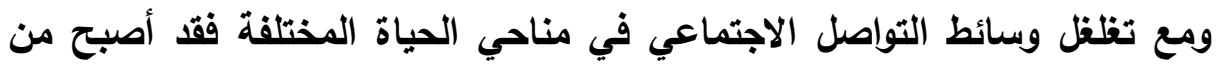
المهم قياس التأثير للمنشورات العلمية الذي تحدثه في تلك الوسائط، وفي المنصات الرقيمية

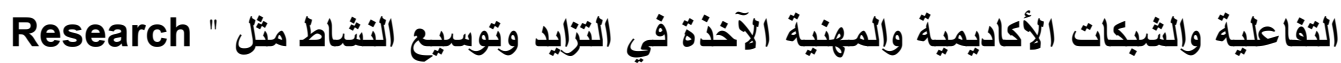
Gate" و "Academia" و "Linkedln"، والتي تتيح إنثاء حسابات شخصية مجانية للباحثين لعرض إنتاجهم العلمي والفكري المحكم وغير المحكم للجمهور بشكل مفتوح ويلغات

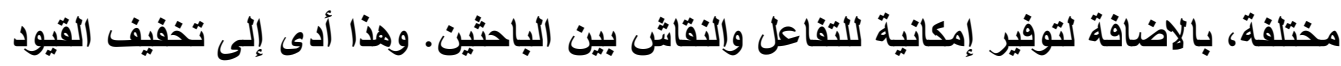
التي فرضها تقليدياً نموذج تقييم النظراء على النشر العلمي ومنح هامشاً لتقييم الانتاج 
البحثي من خلال الجمهور المتلقي. ولم يعد من الخافي القول بأن النمط التقليدي للنشر العلمي وقواعد البيانات المرتبطة به تعاني من قصور في هذا الجانب ومن أبرزها :

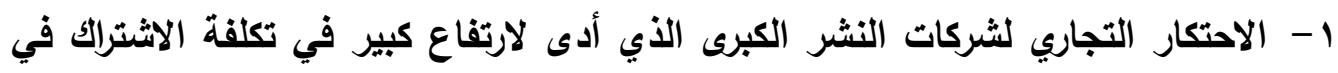

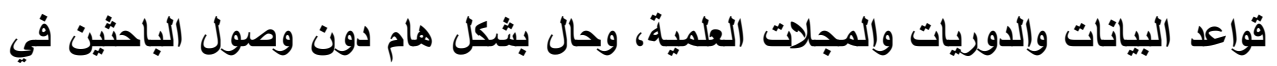

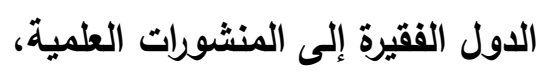
ץ- اعتماد قواعد البيانات الكبرى مثل "TR" و "Scopus" على المجلات والاوريات الصادرة غالباً في الدول الغزبية، مما قد يحدث تحيزات في المواضيع التي يتم تغطيتها، إضافة

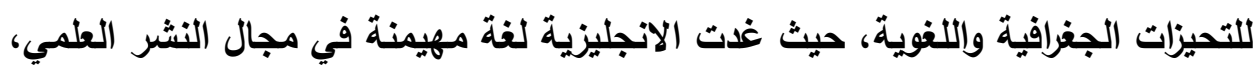

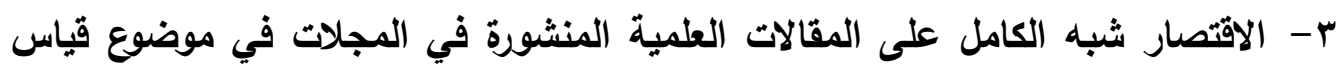
التأثير، دون إيلاء اهتمام كبير لقياس تأثير الكتب والأطروحات والتقارير وما شابهابه، وهو ما يدفع المؤلفين المحتملين نحو تفضيل النشر في المجلات العلمية كونها لا زالت الأكثر ثقلاً في أنظمة الترقية والتثبيت وفي الحصول على التمويل للمشاريع البحثية، ع - التركيز على المنشورات والدوريات العلمية بشكل منفرد مع غياب "بروفايل" اجمالي للباحث وضعف مؤشرات قياس إنتاجه البحثي ككل، مؤثرات قياس إنتاجه البحثي ككل.

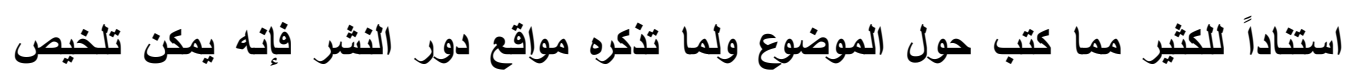

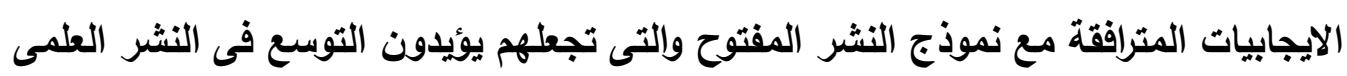

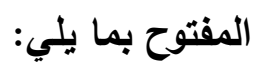
ا - إتاحة الوصول للمنشورات العلمية من أماكن كثيرة حول العالم ، الثيء الذي يكتسب

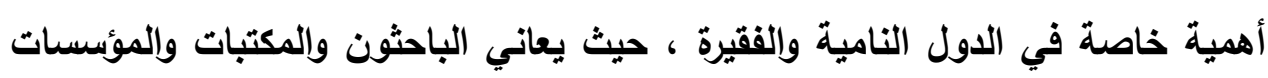

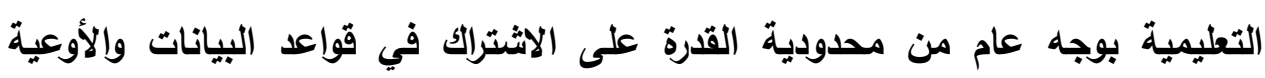
الناشرة لنتائج الأبحاث ، اضافة الى إتاحة وصول الجمهور العادي ومؤسسات المجتمع المدني للتتائج البحثية داخل الدول التي يتم فيها البحث بهدف زيادة تفاعل ذلكاتل الجمهور مع البحث ونتائجه وتوسيع دائرة المعرفة العلمية. r - دعم العملية التعليمية والتدريسية، خصوصاً في مساقات السنوات المتقدمة والدراسات العليا، من خلال إتاحة النتائج والمستجدات البحثية دون مقابل لاستعمال الطلبة والاساتذة في مؤسسات التعليم العالي. 
النشر العلمى المفتوح Open-Access Publishing بين التأييد والرفض.

r- السماح للباحثين بنشر ابحاثهم ومقالاتهم بحرية وسرعة كبيرتين. ع - زيادة عدد الاقتباسات أو الاستشهادات للمقالات والابحاث المنشورة ، الامر الأى يرفع من معامل التاثير للباحث Author IF (او معامل اتش H- Index ) ، معامل التاثير

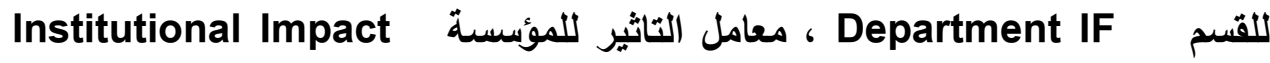

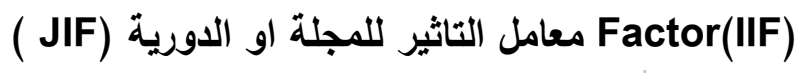

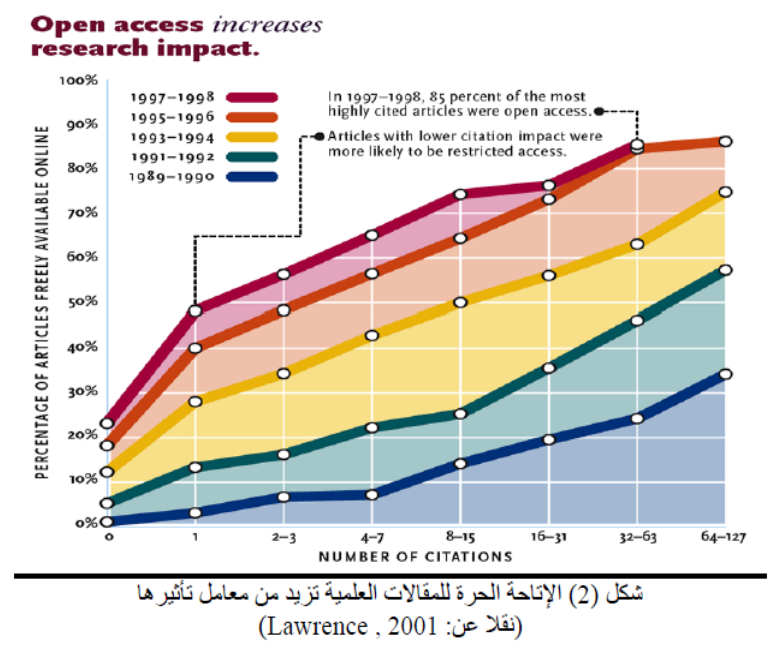

ه- تنشيط وتسريع الدورة البحثية من خلال إتاحة النتائج البحثية أولاً بأول للباحثين حول العالم. צ- المساعدة فى كثف عمليات الانتحال والسرقات العلمية ، فالانترنت بما تقدمه من حرية النشر والتعبير لكل من يرغب بذلك، وفرت فى الوقت نفسه ادوات عديدة لكشف الانتحال والسرقة العلمية. ابعدت عنها اصحاب بحوث النسخ واللصث. حتى اصبح النشر على الانترنت هو الضمانة الاكيدة للحفاظ على الملكية الفكرية للاعمال الادبية والعلمية.!، ان حرية النشر وحرية الوصول الى المعلومات اسهم بشكل غير مباشر الى

$$
\text { منع حالات الانتحال. }
$$

- Vسر احتكار الناشرين لكل من عملية توزيع والوصول إلى الأبحاث العلمية .، تمكين المؤلفين من ضمان بث أعمالهم على نحو متزايد من خلال عرضها ونشرها على أوسع نطاق ممكن، وهذا فضلا عن إمكانية الاحتفاظ بحق النشر، وتقوية وتعظيم الاتصال العلمي بين الباحثين المنتمين إلى تخصصات مختلفة. 


\section{النشر العلمى المفتوح Open-Access Publishing بين التأييد والرفض.}

1- زيادة الخدمات التى يمكن ان تقدمها المكتبات الرقمية لمرتاديه ، من ابرزها إمكانية امتلاك نسخ من الدوريات الالكترونية، بالإضافة إلى إمكانية أرشفة تلك النسخ بشكل دائم ودون الحاجة إلى ترخيص خاص ودفع مقابل مادي بشكل مستمر، وإمكانية حفظ

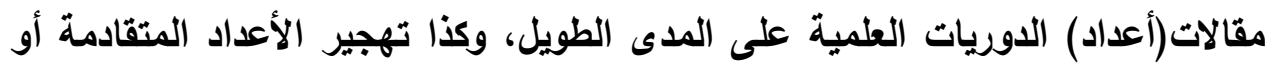
السابقة إلى أثكال ووسائط حديثة تسمح بقراعتها، وهذا فضلا عن أن إمكانية إعارة نسخ عنها، وكذلك عدم تقيد عملية الوصول واستخدام الدوريات الاككترونية مثلا ب: كلمة السر، Internet Protocol address (IP address)، ساعات الاستخدام، الانتساب كعضو لمؤسسة ما، مع إمكانية منح البرمجيات أو المؤلفات العلمية الرقمية، للجامعات دون أن تتنهك هذه الأخيرة قوانين ترخيصها. الماخذ واسباب الرفض :

على الرغم كل المزايا التى يوفرها نظام الوصول والنشر الحر الا ان واقع الممارسة اظهر العديد من الماخذ والتحفظات تمثلت فيما يلى :

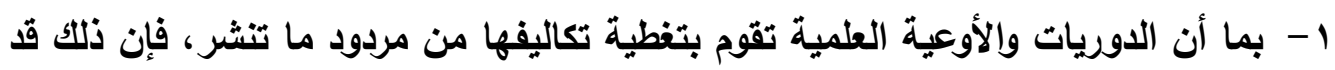
يدفع البعض لنشر عدد كبير من المقالات والأبحاث ويثير بالتالي تحديات ضبط الجودة مردة والتأثير على عملية تقييم النظراء، والتي تعتبر عصب الحياة لحيادية النشر العلمي ونزاهته. وليس خافياً أن مجال النشر العلمي المفتوح يعاني حالياً من انتشار دور نشر

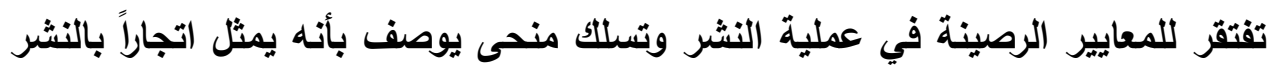
العلمي دون كثير التفات لعملية تحكيم النظراء أو لجودة ما ينشر ـ وفي هذا السياق فإن

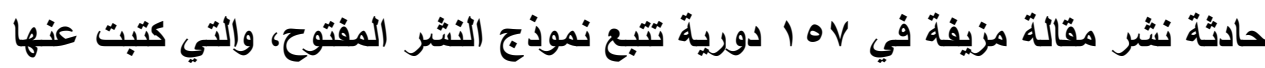

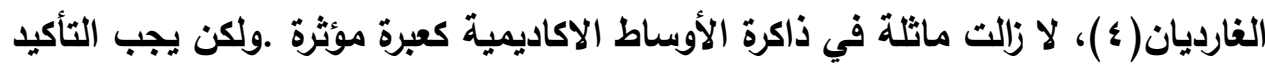

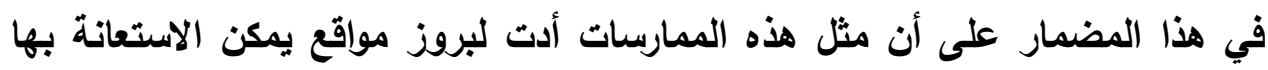

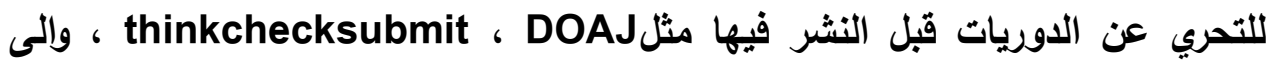
وجود ما يعرف بقائمة بيل توالتي تدرج دور نشر و دوريات علمية

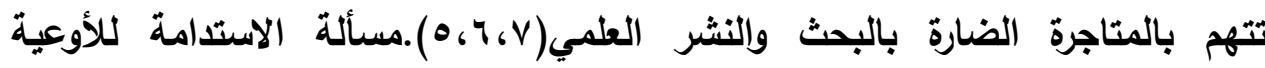
ولشركات النشر . 


\section{النشر العلمى المفتوح Open-Access Publishing بين التأييد والرفض.}

r - يوجد حاليا العديد من دور النشر العالمية التي يظلب عليها ظاهريا النشر العلمي ولكن في الواقع أنها تضع في اولوياتها الاغراض التجارية مما يبعدها عن الرصانة العلمية المطلوية ، وتستدرج هذه الجهات ومجلاتها العلمية الباحثين في الكثير من البلان للنشر فيها، ولعدم وضع الرصانة العلمية ضمن أولويات النشر فإن هذه الدور تنشر البحوث بلون تقييم أو بتقييم ضعيف المستوى ، مما يقلل من الفائدة العلمية لهذه البحوث ويالتالي يؤثز على رصانتها العلمية ، وتقوم هذه المجلات بالنشر الأكتروني في شبكة المعلومات الدولية (الأنترنت ) وتدعي النشر المتاح Open Access و تحمل الباحث أجور نشر باهظة، وقد تكون مجانية تعدد الى سرقة أفكار الباحثين وتطويرها في مؤسساتهم العلمية.

r- هناك الكثير من المشككين في قابلية هذا النموذج للاستمرار لفترة طويلة. فمثلاً يرتبط

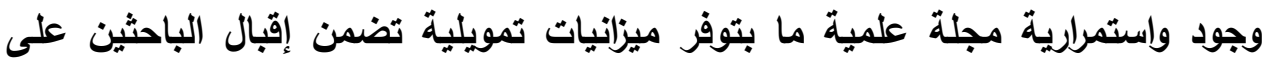
النشر فيها، مما يعني أن عزوف الباحثين عنها لسبب ما قد يؤدي لإغلاقها حتى لو كانت تحرص على النشر بجودة علمية رفيعة.بالإضافة لما سلف ينبغي التوضيح بأن نموذج النشر المفتوح ينظوي على أشكال متعددة لإتاحة المنشورات للقراء ولدرجة احتفاظ المؤلفين بحقوق النشر وإعادة الاستخدام. ـ - من بين الأثكال الأكثر شيوعاً يمكن تعداد الشكل الذهبي والثكل الماسي والشكل الأخضر للنشر المفتوح ، بالنسبة للشكل الأهبي فالمقصود أن نتاح المنشورات للقراء بشكلها النهائي فور قبولها للنشر في الأوعية العلمية. أما الثكل الأخضر، والذي لا يرتبط حصرياً بنموذج النشر المفتوح، فيتطلب انقضاء فترة زمنية معينة قبل إتاحة المنشورات بشكلها النهائي للقراء، مع امكانية أن يقوم المؤلفون قبل ذلك بتحميل نسخ ميخ أولية من منشوراتهم على مستودعات المنشورات التابعة لمؤسساتهم أو لمؤسسات أخرى غير تجارية. أما الثكل الماسي، وهو الأحدث نسبياً والذي يسعى المدافعون عنه لهوله لتخفيف تأثير البعد التجاري لعملية النشر، فيرتبط بإتاحة المنشورات دون أن يتحمل القراء أو المؤلفين تكلفة النشر، الأمر الذي تتم معالجته بجهود تطوعية في الغالب بحيث تصبح عملية النشر غير ريحية(1). 


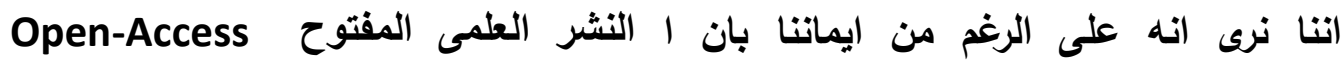
Publishing

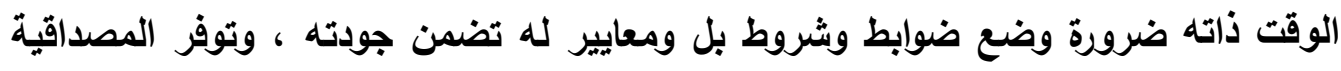

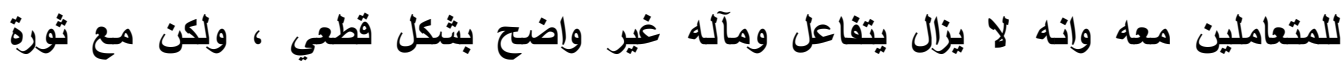
المعلومات الاكترونية وسهولة ما يوصف ب عولمة المعرفة من جهة، وارتفاع تكاليف

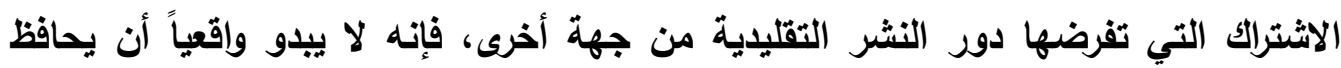

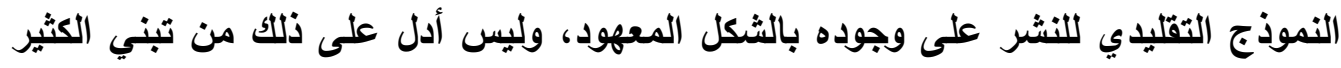

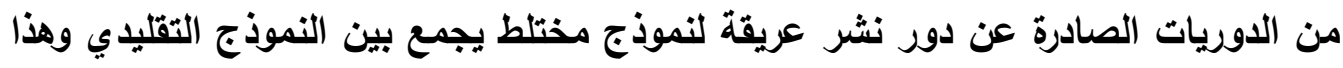
النموذج.

من هنا فإنه ينبغي الانفتاح على موضوع النشر المفتوح جنباً لجنب مع المحاذرة من الوقوع في شرك جهات ناشرة مغورة هدفها تحقيق الريح على حساب جودة ما تنشره. وهذا لأنا

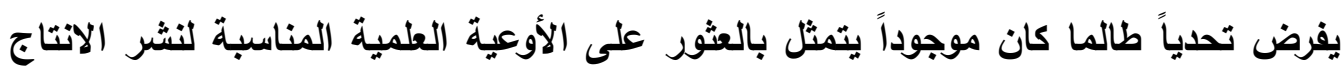

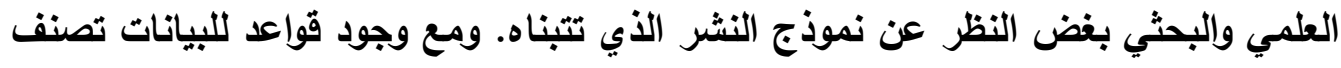

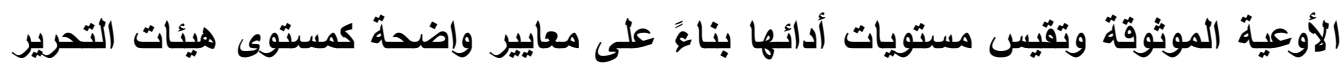

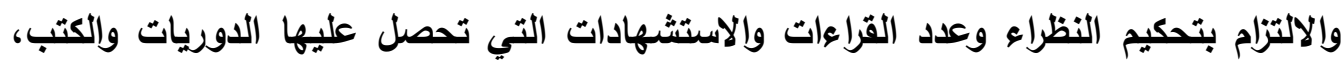
فلعله لاى جمهور المؤلفين المحتملين من هذه الوسائل ومن غيرها ما يعينهر على انتقاء الأوعية المناسبة لنشر نتاجهم العلمي. وفى هذا الاطار يؤكد محمود عبد العاطى على ذلك بقوله "سواء رضينا ام لن نرضى لإنه

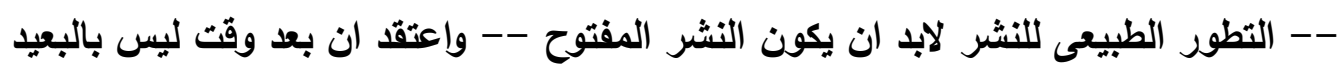

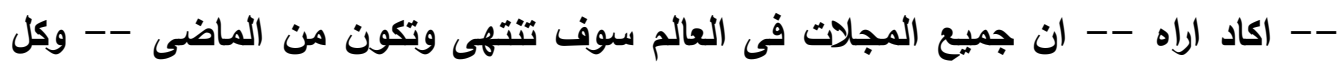
النشر العلمى سوف يكون فى مواقع الكترونية مفتوحة للجميع --- سوف تبقى الاختراعات

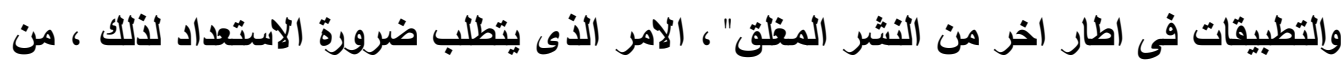

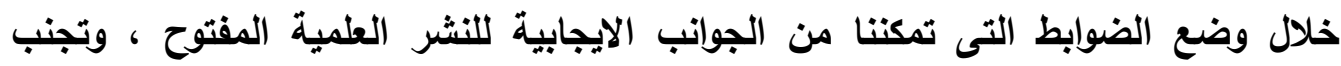

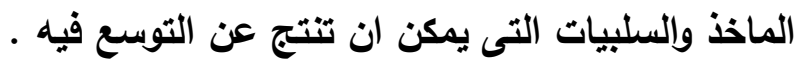




\section{المراجع}

ا - جمال على الدهشان : د جمال الدهثان يكتب النشر العلمى المفتوح Open-Access

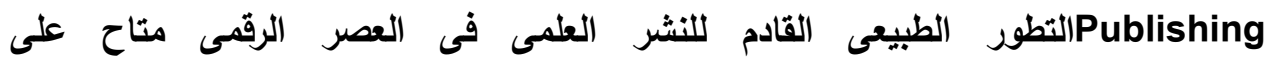
https://www.shbabalnil.com/\%d8\%af\%d8\%ac\%d9\%85\%d8\%a7\%d9\%84r- رضا سعيد مقبل : النثر الجامعي في العصر الرقمية متاح على عله https://faculty.psau.edu.sa/r.mokbel/en/research/rs0000000232 r- شريف كامل شاهين : الملكية الفكرية في بيئة التعلم الإكتروني : نحو مبادرة للإتاحة المجانية للكتب الدراسيةOOpen Textbooks في الجامعات المصرية على شبكة الإنترنت: جامعة لئه

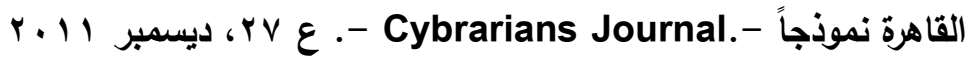

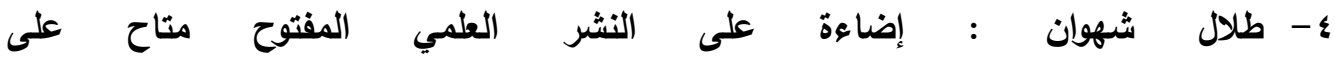
http://www.birzeit.edu/ar/blogs/d-I-Inshr-IImy-Imftwh ه- طلال شهوان : نظرة على مستجدات النشر العلمي في ظل الانفتاح الرقمي متاح على https://www.birzeit.edu/ar/blogs/nzr-I-mstjdt-Inshr-Ilmy-fy-zIInfth-Irqmy

צ- عبد الرحمن فراج : دوريات الوصول الحر ، خدمة الكترونية بدون نفقات - احول المعرفة ـ

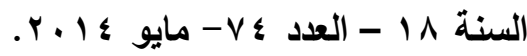
- V - عبد المجيد صالح بو عزة. اتجاهات الباحثين العرب نحو الأرشيف المفتوح والدوريات المتاحة

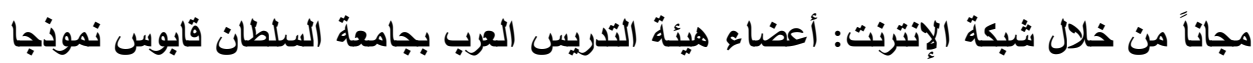

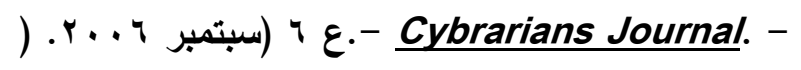

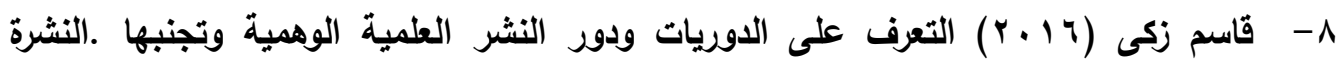
الدورية الإليكترونية الأسبوعية، منظمة المجتمع العلمي العربي، السنة الرابعة، العدد مائة و ولئه

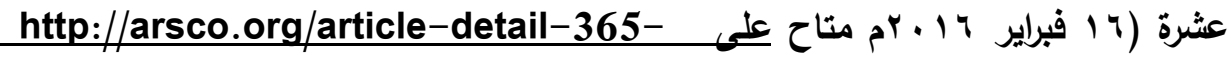

$$
\underline{\text { 8-0 }}
$$

9- قاسم زكى : النشر العلمي الوهمي: بين قائمة بيل...وقانون جريشام 


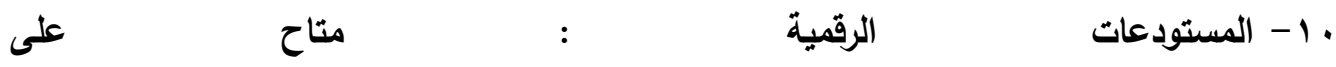
http://numerisations.blogspot.com/2012/05/blog-post_7956.html

11-وسام يوسف بن غيدة : نثأة حركة الوصول الحر للمعلومات العلمية والتقنية - . Cybrarians Journal.r ا-وسام يوسف بن غيدة : الأرثفة الذاتية بالمستودعات الرقمية : جذور الماضي ومعطيات

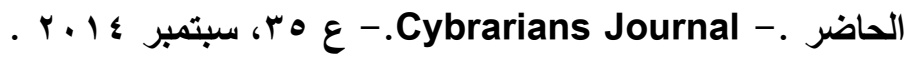

